\title{
LOS OBJETOS DE HUESO DE LA TUMBA 150 DE LA NECRÓPOLIS IBÉRICA DE TÚTUGI (GALERA, GRANADA): ¿INSTRUMENTOS DE ESCRITURA? ${ }^{1}$
}

BONE OBJECTS FROM THE TOMB 150 IN THE IBERIAN NECROPOLIS OF TÚTUGI (GALERA, GRANADA): WRITING INSTRUMENTS?

IGNACIO SIMÓN CORNAGO

Universidad del País Vasco / Euskal Herriko Unibertsitatea

\section{Resumen}

Se propone la posibilidad de que dos piezas de hueso de la tumba 150 de la necrópolis de Tútugi sean instrumentos de escritura, concretamente un estilo y una regla.

Palabras clave. Stilus, instrumentum scriptorium, objetos de hueso, necrópolis ibérica.

\begin{abstract}
This paper suggests that the two bone objects found in the tomb 150 of Tútugi are writing instruments: a stilus and a rule.
\end{abstract}

Key words. Stilus, instrumentum scriptorium, bone artefacts, Iberian necropolis.

Para citar este artículo / To cite this article: Simón Cornago, I. (2016). Los objetos de hueso de la tumba 150 de la necrópolis ibérica de Tútugi (Galera, Granada): ¿instrumentos de escritura?. Lucentum, XXXV, 91-97. doi: 10.14198/ LVCENTVM2016.35.04

Para enlazar con este artículo / To link to this article:

http://dx.doi.org/10.14198/LVCENTVM2016.35.04 


\title{
LOS OBJETOS DE HUESO DE LA TUMBA 150 DE LA NECRÓPOLIS IBÉRICA DE TÚTUGI (GALERA, GRANADA): ¿INSTRUMENTOS DE ESCRITURA? ${ }^{1}$

\author{
GRANADA): WRITING INSTRUMENTS?
} \\ BONE OBJECTS FROM THE TOMB 150 IN THE IBERIAN NECROPOLIS OF TÚTUGI (GALERA,
}

\author{
IGNACIO SIMÓN CORNAGO \\ Universidad del País Vasco / Euskal Herriko Unibertsitatea
}

El objetivo del artículo es tratar de determinar la funcionalidad de dos objetos de hueso recuperados en una de las tumbas de la necrópolis granadina de Tútugi (Galera), pues ambos pertenecen a categorías de instrumentos cuya utilidad es incierta y debatida. Para ello se analiza cada una de las dos piezas de forma particularizada, exponiendo el debate en torno a su clasificación funcional, su tipología y, finalmente, sus paralelos.

Los dos objetos fueron recuperados en el transcurso de las excavaciones de J. Cabré y F. Motos (1920, 5960 ) en la tumba número 150 , ubicada en la zona III del cementerio (ladera oriental, en el acantilado superior). En la monografía de J. Pereira et alii, (2004, 157-161, fig. 102) -en la que se estudian los materiales conservados en el Museo Arqueológico Nacional- se revisa una parte del ajuar recuperado en el enterramiento citado: la urna cineraria, una urna de borde exvasado, un cuenco de borde recto y labio plano, un pequeño vaso caliciforme (todas ellas en cerámica ibérica), una taza de paredes finas, cinco ungüentarios (dos de ellos de vidrio) y las dos piezas de hueso. Además, quedaron sin revisión una segunda urna cineraria, una urna de borde exvasado, dos cuencos-tapadera, un plato de campaniense, una tapadera y fragmentos de bronce, quizá parte de una fíbula (Fig. 1). La cronología que se otorga a los materiales es dispar, pues va desde el siglo -III, en el que se fechan las urnas, hasta época julioclaudia, en la que se sitúa el ungüentario de vidrio azul (tipo 6 en la clasificación de Ising), que se data entre los reinados de Tiberio y Claudio. Precisamente, esta última pieza parece determinar la cronología propuesta para la tumba: «finales s. I. a. C. - comienzos s. I. d.

\footnotetext{
1. Este trabajo se incluye en el proyecto de investigación: Estudios Lingüísticos y Epigráficos sobre Lenguas Paleohispánicas: contextos culturales y lingüísticos (ELELP II), FFI201236069-03. Agradecemos a la Dra. A. Rodero que nos haya facilitado el estudio de estas piezas (conservadas en el Museo Arqueológico Nacional), y a Carlota Lapuente el haber realizado los dibujos.
}

C.», que la convierte en el enterramiento más moderno del cementerio.

Por lo que respecta a las piezas que nos ocupan, la primera es descrita como una «aguja de hueso con cabeza redondeada» y la segunda como una «placa rectangular de hueso con una pequeña arandela perforada en uno de los extremos» (Pereira et alii, 2004, 158). J. Cabré y F. Motos $(1920,60)$ las habían descrito como «un estilete de hueso, $\mathrm{y},(.$.$) una tableta de la misma$ materia, rectangular y con un orificio de suspensión».

\section{EL ESTILO DE HUESO (MAN, N. INV.: 1979/70/ GAL/T.150/2)}

Es una pieza de fuste cónico (con un engrosamiento máximo de $0,75 \mathrm{~cm}$ ) y una longitud de $11,6 \mathrm{~cm}$, con un extremo esférico $(0,8 \mathrm{~cm}$ de diámetro) y otro apuntado, cuyo final está parcialmente perdido (Figs. 2 y 3 ). No puede clasificarse como una aguja, pues carece del necesario ojal, ni tampoco como un acus crinalis, pues no comparte su característica morfología ${ }^{2}$. Pertenece a una categoría de objetos de hueso cuya funcionalidad es debatida. J. C. Béal (1983, 151-162), en su catálogo sobre la industria ósea del museo de Lyon -obra de referencia sobre los objetos de hueso de época romana-, reúne y clasifica como husos una serie de varillas con un engrosamiento central, una punta afilada y, en algunos casos, rematadas por una cabeza globular en su extremo opuesto («tête d'olive»). El autor reconoce que su catalogación como husos no es completamente segura, pues también pudieran ser punzones y se les confunde a menudo con los estilos; indica, no obstante, dos argumentos para rechazar su inclusión entre los instrumentos de escritura: la presencia de una cabeza globular, menos adecuada que una espátula para borrar el texto, y el amplio diámetro de algunas de estas

2. Sobre estas dos categorías de objetos, véase Béal (1983, 163-235). 

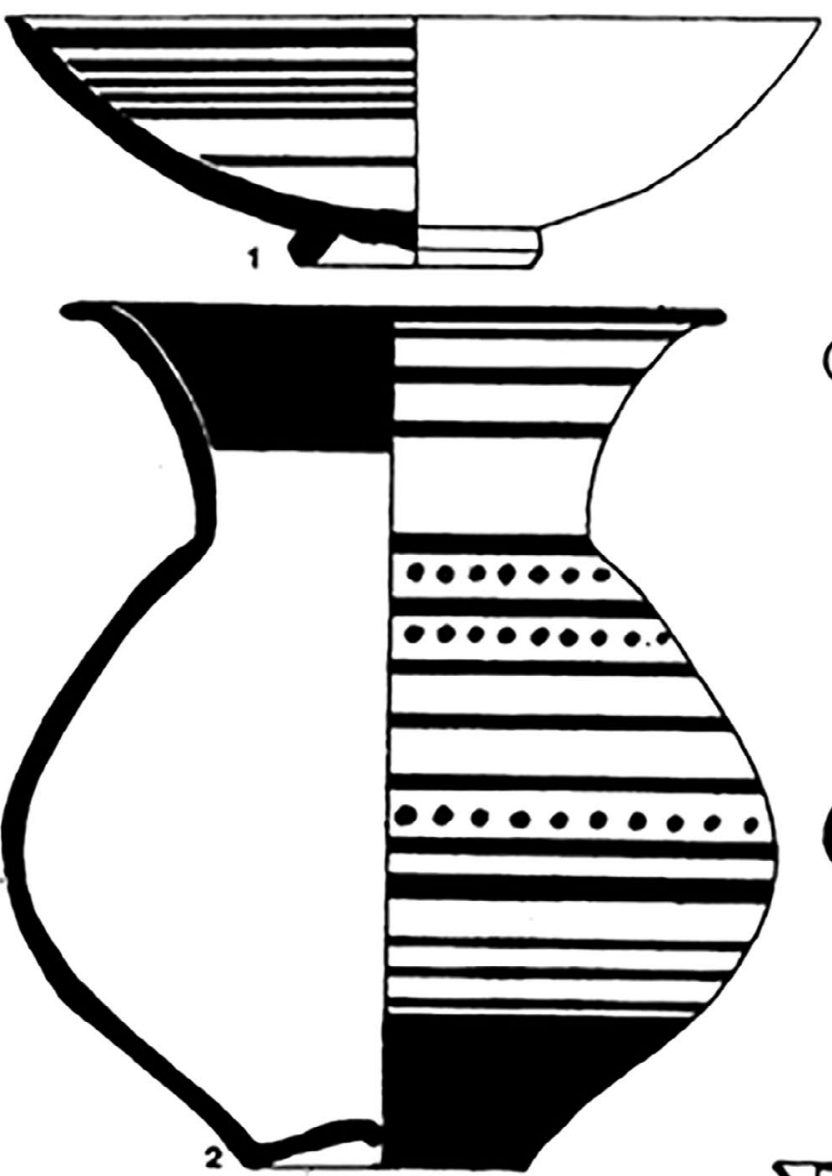

(A)
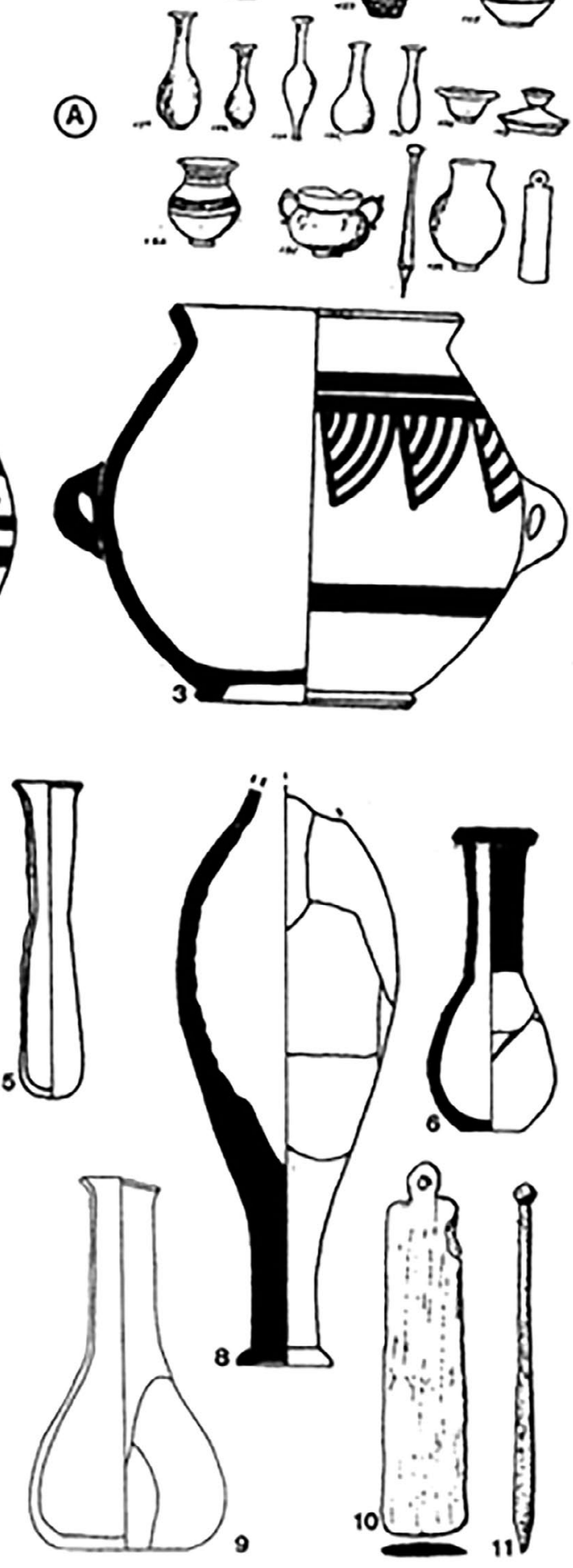

Figura 1: Ajuar de la tumba 150 de Tútugi, según J. Pereira et alii, 2004, fig. 102 (A es el cróquis del ajuar realizado por J. Cabré). N. ${ }^{\circ}$ 1: cuenco de borde recto y labio plano; 2 y 3: urnas de borde exvasado (respectivamente tipo 4-B y 6-A-III de Pereira); 4: pequeño vaso caliciforme (tipo 12-A de Pereira); 5: ungüentario de vidrio de color, grupo 8 en la tipología de Miguélez; 6 y 7: ungüentarios de bulbo con el cuello pintado de color marrón; 8: ungüentario fusiforme, B-6 de la tipología de Cuadrado; 9: ungüentario de vidrio azul, tipo 6 de Ising; 10 y 11: objetos de hueso; y 12: taza de paredes finas, Mayet XC. Las clasificaciones tipológicas son las propuestas por J. Pereira et alii, 2004, 157-158. 
1979/70/GAL/T.150/2

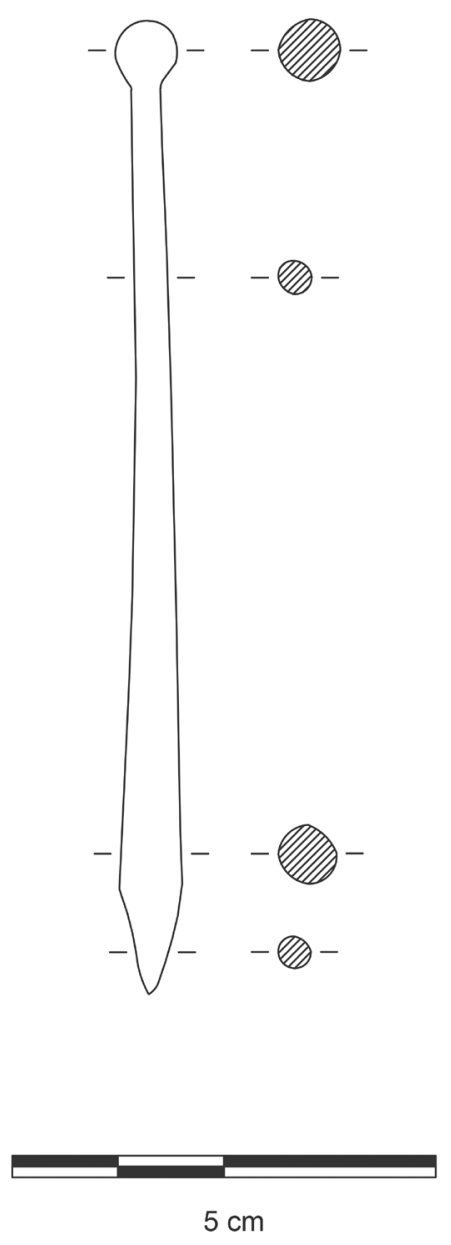

1979/70/T.150/5 GAL.ZONA III

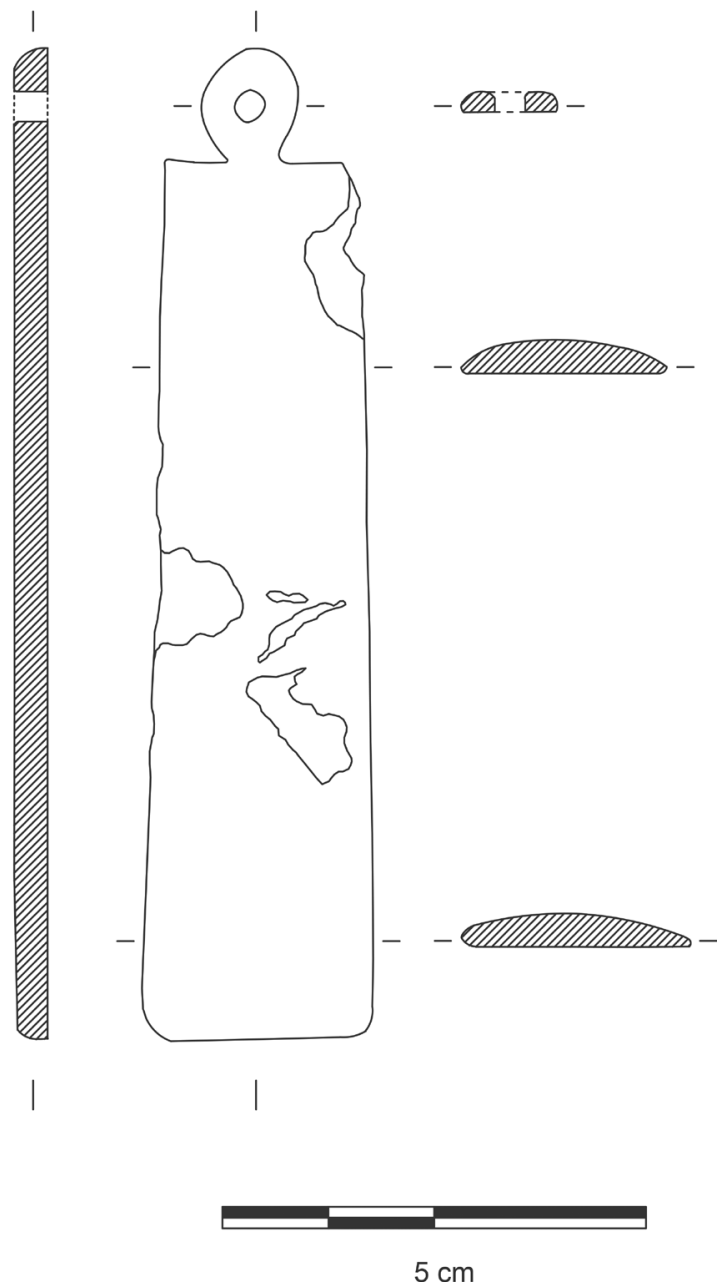

Figura 2: Piezas de hueso de la tumba 150 de Tútugi (dibujos de C. Lapuente).

piezas, que parece excesivo para asirlas con el fin de escribir (Béal, 1983, 151)3.

D. Bočiž y M. Feugère (2004, 30-31) han abordado recientemente este problema y, según estos dos autores, los argumentos esgrimidos por Béal no son concluyentes y, por contra, existen otros que hacen incuestionable la clasificación de estas piezas como estilos: la punta afilada no tienen sentido para un huso, pero sí en unos útiles empleados para escribir sobre la cera y que, además, nunca se han recuperado asociados a fusayolas; un buen numero de estos instrumentos procede de campamentos militares, en los que también se han hallado estilos metálicos y otro tipo de instrumentos de escritura-circunstancia que también se constata en los pecios- pero no elementos relacionados con el hilado; en algunos casos se han podido identificar huellas de mordeduras humanas (Gostenčnik, 2010a, fig.

3. Esta clasificación también fue defendida por S. Greep, aunque en un trabajo posterior ha manifestado su cambio de opinión al respecto (Greep, 2002).
14.8; Schaltenbrand Obrecht, 2012, 54, fig. 48), presumiblemente realizadas por el scriptor e, igualmente, trazas de desgaste en las cabezas globulares, o «tête d'olive», que parecen resultado de haberse empleado para alisar la cera; $y$, finalmente, añaden otra evidencia contextual, pues se han recuperado en determinadas tumbas junto a otros objetos de escritura. Según nuestra opinión, estos argumentos son concluyentes y dicha interpretación concuerda con la clasificación que se hace de este tipo de instrumentos en varios catálogos de cultura material romana realizada en hueso, como la monografía de K. Gostenčnik $(2005,44)$ sobre Magdalensberg o el corpus de H. Mikler (1997, 25) de los fondos del museo de Mainz ${ }^{4}$, aunque ello no

4. También en otros catálogos como los de S. Deschler-Erb (1998) y A. Schenk (2008). La clasificación de estas piezas como estilos era indiscutible en la bibliografía decimonónica y de comienzos del siglo $\mathrm{XX}$, tal y como señala $\mathrm{K}$. Gostenčnik $(2005,44)$; véase a modo de ejemplo la monografía de V. Gardthausen (1911, 126, fig. 8). 


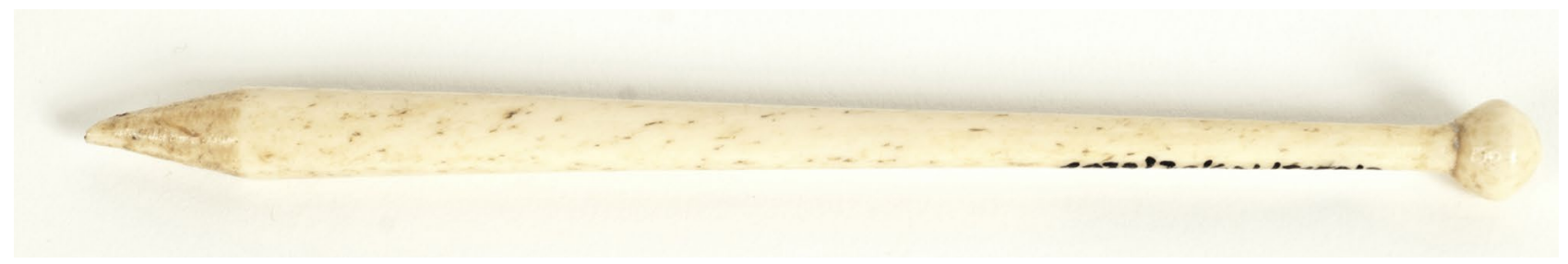

Figura 3: Estilo de hueso de la tumba 150 de Tútugi (MAN 1979/70/GAL/T.150/2; fotografía del Museo Arqueológico Nacional).

es óbice para reconocer que la clasificación funcional de algunos de los ejemplares más sencillos pueda generar ciertas dudas.

Es sorprendente el remate esférico o «tête d'olive» de algunas de estas piezas que, según J.C. Béal (1983, 151), es un argumento en contra de su clasificación como estilos. Sin embargo, el propio autor reconoce que dicho remate está unido al vástago por un cuello muy estrecho, que no soportaría la presión que se ejerce sobre un punzón, si es que esta fuese la funcionalidad de estas piezas; igualmente señala que, aunque pudiera servir para retener los hilos enrollados -si efectivamente se tratase de husos- no sería indispensable, pues no aparece en piezas cuya clasificación como tal es incuestionable. Por último, hay que subrayar cómo el citado autor determina la desaparición en el siglo I de varios de los subtipos que diferencia dentro de este conjunto de instrumentos, algo que encaja bien con lo que conocemos sobre la historia de los estilos, pues los ejemplares de metal parecen sustituir casi por completo a los óseos a lo largo de la primera centuria de la Era (Bočiž y Feugère, 2004, 31; Mikler, 1997, 27; Schaltenbrand Obrecht, 2012, 62). J.C. Béal (1983, 151) también señala que para borrar sería más idónea una espátula que los remates esféricos, pero estos parecen ser más sencillos de producir en un proceso de fabricación para el que se usa el torno (Gostenčnik, 1996, 109-110) y, además, las espátulas sólo parecen emplearse en estilos de hueso de cronología avanzada, que imitan la forma de las piezas metálicas (Mikler, 1997, 25, lám. 15/2).

V. Schaltenbrand Obrecht (2012, 23, fig. 3) ha añadido un nuevo elemento de juicio al debate, se trata de una estatua de Gudea de Lagash, pues en su regazo sostiene una tabilla de escribir y sobre ella hay un instrumento con cabeza en forma de oliva, que por el contexto no puede sino interpretarse como un estilo. Esta representación se une a otra pieza excepcional: un stilus de bronce etrusco procedente de Orvieto. $\mathrm{Su}$ clasificación como tal está fuera de toda duda, ya que entre el fuste y el remate globular se sitúa la representación de un varón que resulta reveladora para este particular (Mikler, 1997, 26, fig. 4; Gostenčnik, 2005, 44, fig. 4): se trata de un personaje estante y desnudo que, en una de sus manos, porta un estilo y, en la otra, un díptico (Szilágyi, 1980, 20, fig. 16). Por tanto, esta cabeza globular, que en este caso termina en punta -lo que le confiere una forma similar a una oliva o bien a una bellota-, se emplearía para borrar los errores de escritura, acción que los autores latinos denominan uertere stilum ${ }^{5}$.

Finalmente hay que añadir un argumento contextual a los mencionados previamente, y que atañe a un estilo con cabeza de oliva recuperado en Italia, en una tumba de Portorecanati (Schaltenbrand Obrecht, 2012, fig. 58). La relevancia de este hallazgo reside en que también formaba parte del ajuar funerario una espátula de hierro, de las que se emplearon para alisar la cera de las tabillas para escribir, lo que refuerza la interpretación del instrumento de hueso como un stilus y no como un huso.

La pieza de Tútugi encaja en la primera variante del tipo 2 de la clasificación de K. Gostenčnik (2005, 65-66), pues su fuste es cónico, algo que parece característico de los ejemplares de época republicana. Las siguientes piezas -que comparten fuste cónico, punta corta e igualmente cónica y un remate esférico- se pueden señalar como paralelos formales de nuestra pieza: tres ejemplares numantinos (Schulten, 1929, 207, 211, 215, lám. 22, n. ${ }^{\circ} 13$, lám. 28, n. ${ }^{\circ} 4$ y lám. 34, n. $\left.{ }^{\circ} 13\right)$, una pieza deliense, que presenta un gran desgaste en la cabeza (Deonna, 1938, 682, n. ${ }^{\circ}$ 5), otra de Aquileia (Schaltenbrand Obrecht 2012, Aq26), y una última de Auenticum (Schenk, 2008, n. ${ }^{\circ}$ 484).

\section{LA PLACA DE HUESO (MAN, N. ${ }^{\circ}$ INV.: 1979/70/T-150/5)}

La segunda pieza es una placa de hueso ligeramente trapezoidal y cuya sección tiene forma de segmento circular, con las siguientes dimensiones: $10,5 \mathrm{~cm}$ de longitud, anchura de 2,3 y 2,7 cm y grosor de $0,4 \mathrm{~cm}$. En uno de sus extremos está rematada por un anillo de $1,3 \mathrm{~cm}$ de diámetro, con una perforación circular de $0,3 \mathrm{~cm}$ de diámetro (Figs. 2 y 4 ).

La funcionalidad de este tipo de placas óseas aún es más discutida que la de los instrumentos que hemos defendido clasificar como stili. Se trata de piezas rectangulares o trapezoidales, de sección lenticular o trapezoidal y rematadas en su extremo por un apéndice, habitualmente circular. Por norma el citado apéndice está perforado y puede denominarse capitulum, a

\footnotetext{
5. Sobre las referencias de los autores clásicos a los stili, véase la entrada de G. Lafaye (1918) en el Dictionnaire des Antiquités.
} 


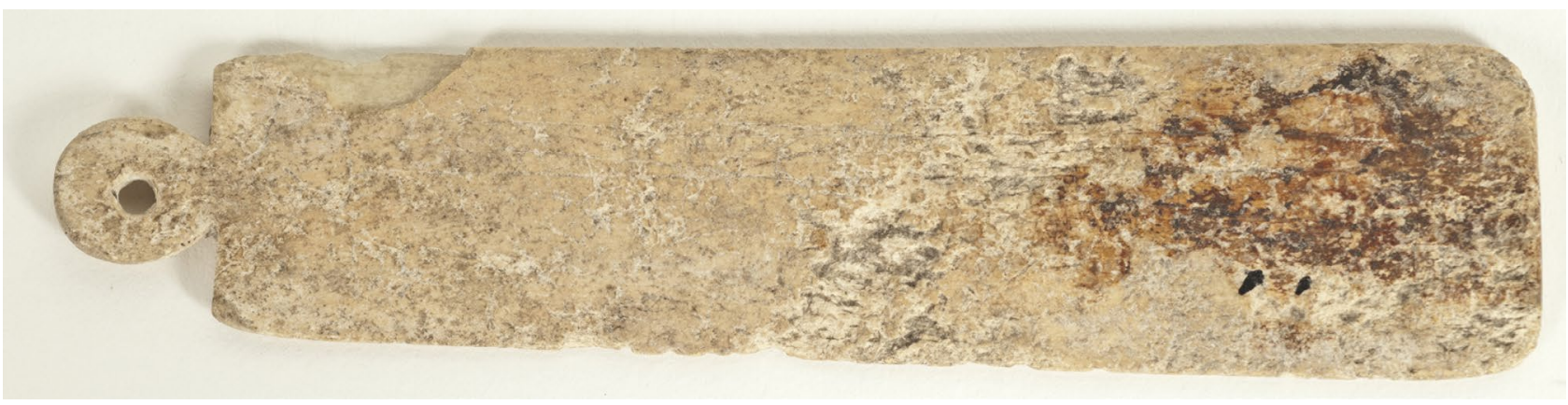

Figura 4: Placa de hueso de la tumba 150 de Tútugi (MAN 1979/70/T-150/5; fotografía del Museo Arqueológico Nacional).

juzgar por la descripción que Varrón (Rerum Rusticarum III, 5,10$)^{6}$ hace de las tabulae cum capitulo, que se asemejan formalmente a nuestras piezas, que se documentan en algunas pinturas de Pompeya y cuyo formato copian algunas inscripciones broncíneas como las téseras pagánicas (Costabile y Licandro, 2000, 25-34; Beltrán, 2010, 208-209). Precisamente es una pintura pompeyana la que atestigua que la función de este orificio era el de suspender las tabillas de escritura (Quaranta 1924: lám. 12, n. ${ }^{\circ}$ 2).

Por lo que respecta a la cronología de las piezas de hueso, se documentan entre los siglos I y III. Las funcionalidades que se han atribuido a este tipo de piezas han sido muy diversas: cortapapeles, encuadernador, etiquetas (por su parecido con las tesserae nummulariae), tesserae lussoriae, tapaderas de cajas de hueso e instrumentos de tejedor?.

Son diversas las objeciones que pueden plantearse a las propuestas enumeradas. La posibilidad de que sean piezas empleadas en las labores de encuadernación no parece plausible por su cronología, pues son anteriores a la difusión y popularización del codex (Božič y Feugère, 2004, 39). Tampoco parece que se puedan clasificar como tesserae, ni lussoriae ni nummulariae, pues, aunque también son piezas realizadas en hueso y existe cierto parecido formal, una de las características comunes a estos dos grupos es el de estar inscritos, pero sobre las placas que nos ocupan no se ha documentado inscripción alguna, ni grabada ni pintada (Deschler-Erb, 1998, 153; Gostenčnik, 2005, 243). Además, el tamaño de las tesserae citadas es sensiblemente menor y la perforación también es diferente, con un pequeñísimo orificio que atraviesa

6. Deformatus ad tabulae litterariae speciem cum capitulo (...), quaad capitulum rutundum est. (Edición de Goetz, 1929).

7. Un resumen de las propuestas en J.C. Béal $(1983,373)$, D. Božič (2001; 2002, 34-35), D. Božič y M. Feugère (2004, $39-40)$ y A. Schenk $(2008,55)$. La opción que ha gozado de mayor predicamento es la que las cataloga, con más o menos convicción, como etiquetas: Obmann, 1997, 76, n. ${ }^{\circ} 1474$ 1477, lám. 39; y Deschler-Erb, 1998, 153-154, n. ${ }^{\circ} 1968$ 1974, lám. 28; también Carnap-Bornheim, 1994, 350-351, n. ${ }^{\circ} 8-12$, aunque entre las piezas que incluye no hay ninguna con el característico apéndice circular. la pieza en sentido opuesto al de nuestros ejemplares (Pedroni, 1995, 161-184; Gostenčnik, 2005, 246-261, láms. 59 y 60). Por su parte, la opción de que se empleasen como tapaderas choca con el hecho de que carezcan de un pomo, habitual y característico en estas piezas (Božič y Feugère, 2004, 40).

Finalmente, K. Gostenčnik (2005, 243-244; 2010, $152-155)^{8}$ ha defendido que sean útiles empleados en las labores textiles, pues son similares a ciertas placas que tradicionalmente se han interpretado como espátulas de telar (lames de tisserand o Webschwerter), de hecho, en ocasiones se han catalogado de forma conjunta. Sin embargo, estas últimas se caracterizan por una sección con forma de segmento circular, la presencia de uno o dos orificios en el dorso y un extremo biselado al que, en algunos ejemplares, se añade un borde dentado (Božič y Feugère, 2004, 40) ${ }^{9}$; además, hay detalles significativos que individualizan a nuestros ejemplares, como los bordes rectos y el apéndice circular, habitualmente perforado para su suspensión ${ }^{10}$.

Finalmente, se ha defendido que sean instrumentos relacionados con la escritura, aunque no se empleasen en el proceso de encuadernación. Esta posibilidad fue planteada por L. Nagy al publicar los materiales de una tumba de Testvérhegy (Budapest), en la que aparecían otros instrumentos de escritura: un tintero, un stilus férreo y restos de una tablilla de cera (Božič y Feugère, 2004, 40). D. von Boeselager (1989, 227228, fig. 14) también defendió dicha hipótesis cuando identificó este tipo de piezas en el monumento de L. Cornelius Atimetus. Pero ha sido D. Božič (2001; 2002; Božič y Feugère, 2004, 39-40) el que ha planteado la cuestión de modo sistemático, reuniendo diferentes argumentos en su defensa, tanto contextuales como iconográficos.

8. También plantea dicha posibilidad C. Meystre $\left(1995,93, n{ }^{\circ}\right.$ $15)$.

9. Sobre estas piezas: Béal, 1983, 371-372; Alfaro, 1984, 105106, fig. 84; y Gostenčnik, 2005, 236-241.

10. En ocasiones se catalogan conjuntamente con otras láminas de hueso, con las que no puede asegurarse que compartan funcionalidad (Obmann, 1997, 76, n. ${ }^{\circ}$ 1474-1477, lám. 39; Deschler-Erb, 1998, 153-154, n. ${ }^{\circ}$ 1968-1974, lám. 28; Gostenčnik, 2005, 235-245, láms. 55-58). 
Por lo que respecta a los contextuales, D. Božičic señala cómo aparece junto con otros instrumentos de escritura en diferentes tumbas: Berlingen (Bélgica), Nijmegen (Holanda), tumba 21 de Duklja (Montenegro), tumba 21 de Brescia (Italia; Božič, 2001, 24), Dolenjska (Eslovenia; Božič, 2002), Szöny y Obuda (Hungría; Božič, 2002, 34), y la tumba 15 de la Via Cappuccini en Brindisi (Božič, 2002, 35) ${ }^{12}$. También se atestigua la asociación de estas piezas con otros instrumentos de escritura en la «Bottega di Verus», en Pompeya (Božič, 2002, 35).

Por lo que respecta a la iconografía, como ya se ha comentado, fue D. von Boeselager (1989) el que identificó este tipo de piezas en el monumento de L. Cornelius Atimetus (Museos Vaticanos), en el que también aparecen otros instrumentos de escritura como las espátulas para alisar la cera de las tablillas. Božič (2001, fig. 2) añade otra imagen a la discusión: el fresco de la tumba de C. Vestorio Prisco (Pompeya), en el que está representada una mesa sobre la que aparece un díptico de tabillas enceradas y una placa con remate circular -que puede identificarse con una de nuestras piezas-, además de lo que parece ser una espátula para alisar la cera de las tabulae.

D. Božič (2001, 23; 2002, 34-35) diferencia dos tipos formales de cronología sucesiva. En palabras de D. Božič y M. Feugère $(2004,40)$ : «le type le plus ancien, datable du $I^{e r}$ s. et de la première moitié $d u I I^{e}$ $s$., se caractérise par une petite oreille circulaire (ou en forme de coquille) et par une plaque rectangulaire ou trapézoïdale, plus large en bas. La longueur se situe généralmente entre 13 et $14,5 \mathrm{~cm}$, la largeur entre 2,5 et 3,5 cm», mientras que el segundo tipo «fabriqué au III $s$. et peut-être dès la seconde moité du $I^{e}{ }^{S}$., diffère du type précédent par son appendice (circulaire, ovale, ogival ou en forme de pelte) de même largeur que la plaque, et très rarement percé d'un ou de deux trous (...) La plaque est rectangulaire ou trapézoïdale et, dans ce cas, habituellement plus large au sommet. Le type récent est en général plus long (16 à $19 \mathrm{~cm})$ et plus étroit $(1,5$ à 2,5 cm) que le type ancien» ${ }^{13}$. La forma de la pieza de Tútugi y su cronología encaja bien en la clasificación expuesta, pues responde al primer tipo, característico de los dos primeros siglos del Imperio. Los mejores paralelos para el ejemplar granadino son varias piezas de Vindonissa (Božič y Feugère, 2004, fig. 35) así como la recuperada en la tumba 15 de la necrópolis de Via Cappuccini de Bari (Cocchiaro, 1988, n. ${ }^{\circ}$

11. Sobre este tipo de contextos funerarios, véase también Fünfschilling, 2012, 169-175, tabla 2, fig. 5.

12. Sin embargo, su editora la clasifica como un elemento de juego, aunque no específicamente como una tessera lusoria (Cocchiaro, 1988, 171, n. $\left.{ }^{\circ} 304\right)$.

13. Sobre la fabricación de este tipo de piezas, véase el trabajo de Ph. Prévot (2010) y también K. Gostenčnik (2010, 152-154).
304), pues comparte con ellas la placa trapezoidal y el anillo de pequeño tamaño.

$\mathrm{Su}$ asociación en tumbas y en la iconografía con otros instrumentos de escritura son indicios para clasificarlo entre estos últimos, pero queda por determinar cuál sería su función concreta. D. Božič y M. Feugère $(2004,39-40)$ han sugerido que se emplease como guía para trazar líneas rectas, aunque no servirían para medir puesto que no están graduadas ${ }^{14}$.

\section{CONCLUSIÓN}

Las piezas analizadas tienen una funcionalidad incierta y debatida. Sin embargo, los avances en el estudio de la industria ósea romana y, especialmente, el creciente interés por los instrumentos de escritura ofrecen argumentos suficientes para defender su clasificación entre estos últimos, como un estilo y, plausiblemente, como una regla. Las razones, como se ha detallado en el cuerpo del trabajo, son de índole morfológica, contextual y también iconográficas. $\mathrm{Su}$ asociación en esta tumba de Galera también es significativa al respecto, pues casa bien una misma función para ambas piezas, con lo que se pueden equiparar con otros juegos de instrumentos de escritura conformado parte de un mismo ajuar funerario. Se une pues a una serie de tumbas cuyos ajuares funerarios incluyen equipos de escritura. Su estudio ha sido fundamental para determinar la funcionalidad de algunos de estos objetos (Fünfschilling, 2012, 169-175, tabla 2, fig. 5), como es el caso de la segunda pieza de Tútugi, pero aún queda por evaluar el significado del propio hecho de que se depositen instrumentos de escritura en las tumbas, en función de una serie de parámetros relevantes, como el sexo del difunto, su edad y su categoría social. En el caso de Galera, el enterramiento fue exhumado en excavaciones desarrolladas a comienzos del siglo pasado y no se realizaron análisis de los posibles restos óseos que pudieron sobrevivir a la incineración. Sí es muy reseñable la aparición de estos instrumentos de escritura en Tútugi, pues el uso de este tipo de objetos en la cultura ibérica apenas está documentado, aunque a este respecto hay que recordar que la tumba 150 es la más tardía del cementerio y se data ya en época imperial (reinado de Augusto).

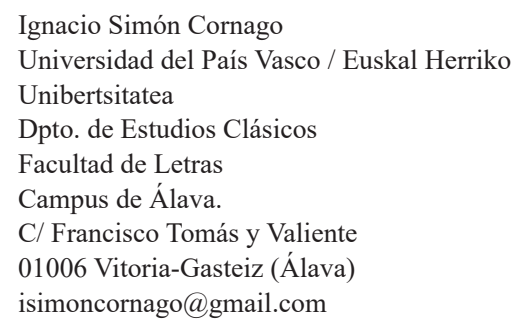

14. Se une a esta interpretación Fünfschilling, 2012, 195-196. 


\section{BIBLIOGRAFÍA}

ALFARO, C., 1984: Tejido y cestería en la Península Ibérica, Madrid.

BELTRÁN LLORIS, F., 2010: «Tesserae paganicae», en L. Lamoine, C. Berrendonner y M. Cébeillac-Gervasoni (eds.), La praxis municipale dans l'Occident Romain, 187-210, Clemont-Ferrand.

BÉAL, J. C., 1983: Catalogue des objets de tabletterie du Musée de la Civilisation Gallo-Romaine de Lyon, Lyon.

BOESELAGER, D. von, 1989: «Funde und Darstellungen römischer Schreibzeugfutterale zur Deutung einer Beigabe in kölner Gräben», Kölner Jahrbuch für Vor-und Frühgeschichte, 22, 221-239.

BOŽIČ, D., 2001: «Su un bastoncello appiattito in osso da Aquileia (I)», Instrumentum, 14, 23-24.

BOŽIČ , D., 2002: «A Roman grave with writing implements from Ljubljana (Sl)», Instrumentum, 16, 33-36.

BOŽIČ, D. y FEUGÈRE, M., 2004: «Les instruments de l'écriture», Gallia, 61, 21-65.

CABRÉ, J. y MOTOS, F., 1920: La necrópolis ibérica de Tútugi (Galera, Provincia de Granada), Madrid.

CARNAP-BORNHEIM, C. von, 1994: «Die beinernen Gegenstände aus Kastell und Vicus in Niederbieber», Bonner Jahrbücher, 194, 341-395.

COCCHIARO, A., 1988: «La necropoli», en A. Cocchiaro y G. Andreassi (eds.), La necropoli di via Cappuccini a Brindisi, 63-229, Brindisi.

COSTABILE, F. y LICANDRO, O., 2000: Tessera Paemeiobrigensis. Un nuovo editto di Augusto dalla 'Trasduriana provincia'e l'imperium proconsulare del princeps, Roma.

DEONNA, W., 1938: Exploration archéologique de Délos faites par l'École Française d'Athènes. Le mobilier délien, Paris.

DESCHLER-ERB, S., 1998: Römische Beinartefakte aus Augusta Raurica, Augst.

FÜNFSCHILLING, S., 2012: «Schreibgeräte und Schreibzubehör aus Augusta Raurica», Jahresberichte aus Augst und Kaiseraugst, 33, 163-236.

GARDTHAUSEN, V., 1911: Das Buchwesen im Altertum und im byzantinischen Mittelalter, Leipzig.

GOSTENČNIK, K., 1996: «Die Kleinfunde aus Bein vom Magdalensberg», Carinthia, 1, 105-137.

GOSTENČNIK, K., 2005: Die Beinfunde vom Magdalensberg, Klagenfurt.
GOSTENČNIK, K., 2010a: «The Magdalensberg Textile Tolls: a Preliminary Assessment», en North European Symposium for Archeological Textiles X, 73-90, Copenhagen.

GOSTENCLNIK, K., 2010b: «Ribs as a Raw Material in Roman Bone artefacts from Virunum (Southern Austria)», en Ancient and Modern Bone Artefacts from America to Russia, 149-157, Oxford.

GREEP, S., 2002: «Bone styli», Lucerna, 24, 11-12.

LAFAYE, G., 1918: «Stilus», en Ch. Daremberg y E. Saglio, Dictionnaire des Antiquités Grecques et Romaines IV.2, 1510-1511, Paris.

MEYSTRE, C., 1995: «Le mobilier en os et en métal», $B u$ lletin de l'Association Pro Aventico, 37, 89-104.

MIKLER, H., 1997: Die römischen Funde aus Bein im Landesmuseum Mainz, Montagnac.

OBMANN, J., 1997: Die römischen Funde aus Bein von Nida-Heddernheim, Bonn.

PEREIRA, J., CHAPA, T., MADRIGAL, A., URIARTE, A. y MAYORAL, V. (eds.), 2004: La necrópolis ibérica de Galera (Granada). La colección del Museo Arqueológico Nacional, Madrid.

PEDRONI, L., 1995: «Tessere da una collezione privata», Archeologia classica, 47, 161-201.

PRÉVOT, Ph., 2010: «Un atelier de fabrication de règles en os dans une villa gallo-romaine de Cuperly (Marne)? Étude technologique d'ébauches de règles réalisées en série», Revue Archéologique de l'Est, 59, 539-565.

QUARANTA, B., 1824: Pitture che rappresentano alcuni istrumenti da scrivere, Real Museo Borbonico 1, Napoles.

SCHALTENBRAND OBRECHT, V., 2012: Stilus. Kulturhistorische, typologisch-chronologische und technologische Untersuchungen an römischen Schreibgriffeln von Augusta Raurica und weiteren Fundorten, Augst.

SCHENK, A., 2008: Regard sur la tabletterie antique. Les objects en os, bois de cerf et ivoire du Musée Romain d'Avenches, Avenches.

SCHUlTEN, A., 1929: Numantia. Die Ergebnisse der Ausgrabungen 1905-1912. IV Die Lager bei Renieblas, München.

SZILÁGYI, J. G., 1980: «Un style etrusque en bronze», Bulletin du musée hongrois des Beaux-Arts, 54, 13-27.

VARRÓN, Rerum Rusticarum, ed. D. Goetz, Leipzig, 1929. 